\title{
Lo humano y no-humano en Poemas y antipoemas de Nicanor Parra*
}

\author{
Human and non-human in Poemas y antipoemas of Nicanor Parra
}

\section{Pilar Valenzuela Rettig}

\begin{abstract}
Doctorada en Ciencias Humanas por la Universidad Austral de Chile, Valdivia, Chile. Estudiante postdoctoral de la Universidad de la Frontera, Temuco, Chile.

Correo electrónico: valenzuela.pilar@gmail.com
\end{abstract}

En este artículo se realiza una lectura interdisciplinaria, desde la literatura y la antropología, de la obra Poemas y antipoemas de Nicanor Parra. Se postula que en la obra existe una crítica de la relación que establece el ser humano con lo no-humano, ya sea este creado por el ser humano o elemento de la naturaleza; esta crítica se presenta a través de estrategias textuales propias de la antipoesía y del mensaje.

Palabras claves: antropología, antipoesía, Nicanor Parra.

This article offers an interdisciplinary reading, from literature and anthropology, the work Poemas y antipoemas is Nicanor Parra. We hypothesize that in the work there is criticism of the relation that man with the non-human, whether it is created by man or nature element, this criticism is presented through their own textual strategies of antipoetry and message.

Key words: literature, anthropology, antipoetry, Nicanor Parra.

\section{INTRODUCCIÓN}

En este artículo se aborda una de las tantas lecturas posibles de la obra de Nicanor Parra: la relación del ser humano con lo no humano. Desde una lectura interdisciplinaria del texto Poemas y antipoemas, con códigos interpretativos de teoría literaria y de antropología, se postula la siguiente hipótesis: en el texto Poemas y antipoemas se presenta una crítica a la relación que establece el ser humano con lo no-humano, sea este último objeto creado por el ser humano o parte de la naturaleza;

* El presente artículo se realizó a partir del trabajo evaluativo del curso “Antropología de las cosas que producen palabras” (2010) dictado por el Dr. Juan Carlos Skewes en el Programa de Doctorado en Ciencias Humanas mención Discurso y Cultura de la Universidad Austral de Chile. Se contó con el apoyo de Beca CONICYT, Programa Capital Humano Avanzado. 
la crítica se presenta mediante estrategias textuales propias de la antipoesía y el mensaje. Desde una metodología de análisis semiótico, con códigos interpretativos de teoría literaria y de pensamiento antropológico, se analiza la obra, considerándola como ecopoemas o antipoesía, pero enfocándonos en la mirada antropológica: en el ser humano y su relación con lo no-humano. A partir de una lectura semiótica, basada en la intención de la obra (Eco 1992), se usan categorías de análisis que dan cuenta de la relación entre lo humano y no-humano, presentándose de manera independiente y ejemplificándose con los poemas de mayor pertinencias, para concluir con un análisis general.

\section{PARRA y El PROYECTO ANTIPOÉTICO}

Nicanor Parra (1914) es uno de los escritores chilenos más importantes dentro de la historia literaria del país e Hispanoamérica, prueba de ello son los múltiples reconocimientos que ha recibido, entre los que destacan el Premio Nacional de Literatura (1969), Premio Miguel de Cervantes (2011) y Premio Iberoamericano de Poesía Pablo Neruda (2012). Su proyecto poético, la antipoesía, es su gran legado y lo ha situado como una de las figuras centrales de la renovación de la escritura poética en Hispanoamérica (Carrasco 1990: 15): corresponde a una escritura elaborada a partir de la negación de los rasgos esenciales de otras escrituras y discursos, tanto literarios como no literarios, constituyendo una contradicción, un contratexto (Schopf s.f.); una escritura compleja, multiforme, polidimensional, transtextual, en permanente movimiento de transformación, contradicción, refutación, autocrítica, etc. que puede ser interpretada mediante diversos modelos de la realidad, como física, cultural o textual (Carrasco 1990: 17).

Para definir y comprender el proyecto antipoético es útil recurrir, como lo hace Carrasco (id.), a uno de sus principales antecedentes: la teoría de la antimateria del Premio Nobel de 1993, Paul Durac. Junto a otros científicos ha demostrado la existencia de la antimateria, la cual no se traduce sólo en antineutrones, antielectrones, antiprotones... sino, como opina Durac, posiblemente en antiestrellas, antiplanetas y antihombres. Carrasco indica que así como puede considerarse la antimateria es a la materia, la antipoesía es a la literatura: el texto antipoético es antiliterario, en cuanto se opone a la tradición literaria. El antipoema se constituye en torno a otro texto u textos, a través de una instancia antipoetizante que se concretiza mediante la reescritura (por homologación falsa, inversión y deformación satírica) de un texto, género, estereotipo, referente u conjunto de estos (Carrasco 1990 y 1999).

El antipoema, como ejercicio de reescritura de otro texto, se construye a partir de una “deformación satírica de los modelos”. Carrasco (1999: 61), una inversión textual de una literatura, mediante la inversión del modelo; es decir, lo deforma de modo grotesco, caricaturesco, con crueldad, dejando el modelo en ridículo, degradándolo, en fin, desmitificando la literatura. La desmitificación implica la "desacralización del Yo Poético”, que Schopf (s.f) considera como uno de los elementos, junto a la (re)incorporación de la oralidad, que más causó atención e impacto al presentarse el proyecto en el campo literario con Poemas y antipoemas. Tanto la desmitificación de la literatura como la desacralización del yo poético se entienden bajo el carácter deconstructivo que Vásquez (2012) determina en el proyecto antipoético. Para el autor, la antipoesía es un contratexto o contradiscurso lírico, donde ya no habla el 
nerudiano yo heroico de la naturaleza gestándose, sino el sujeto moderno, irónico y sarcástico, cuyo discurso se traduce en una respuesta a una época donde todo, incluso el lenguaje, se ha vuelto problemático y difuso.

Como respuesta a un mundo problemático y difuso, el antipoema adquiere una función de “corrección de la sociedad”, que según Carrasco (1990: 61) se expresa mediante la sátira que corrige, fustigando los servicios, limitaciones y defectos de la sociedad. Y así lo da a entender el mismo Parra, a nivel metatextual, en una entrevista realizada en 1989 por Morales (1990), donde proclama su visión del poeta como "fabricante de pancartas"; manifestando que la poesía "siempre tiene que cumplir una función”, ya sea como "un mecanismo de autorregulación del espíritu”, "toma de conciencia” o "retroalimentación del espíritu” (id.: 129).

Esta imagen del poeta como "fabricante de pancartas" se condice con la visión nacionalista que Ayala (2005) determina como la figura literaria que Parra quiso adquirir como personaje público: una mezcla híbrida de la figura del profesor degradado y de la del festivo cantor popular. Según el autor, a pesar de ser figuras contradictorias, ambas son imágenes configuradas nacionalmente que constituyen figuras de transmisión de conocimientos. En el mismo sentido, Morales (2012) destaca la cercanía con el lector y el efecto de "verdad" del discurso de la antipoesía de Parra.

\section{LA “PANCARTA ECOLÓGICA" DE PARRA}

Parte de los conocimientos que Parra expone en sus "pancartas” corresponde a un mensaje ecológico. Un estudio de los ecopoemas de Parra (parte del proyecto antipoético) realizado por Araya (2008) desde la ecocrítica, determina que los textos forman un discurso ecológico. Para el autor, Parra ha contribuido a poner en discusión, desde la poesía, aquello que ha sido motivo de foros y programas que han buscado una solución alternativa a los problemas ambientales. Mientras los foros y programas se dan en un ámbito restringido, la poesía es abierta a quien desee buscar en ella no sólo el lirismo, sino además respuestas a problemas contingentes (id.: 17).

El mismo Parra, en una conferencia dictada en un liceo de Temuco en 1985, pone énfasis en comunicar a los jóvenes el problema que en ese momento lo acoge: el problema de la supervivencia, el problema de la naturaleza (Carrasco 1999: 4055). Frente a este problema expone una crítica a la literatura ajena a la realidad, a la literatura que se presenta pasiva e ilusoria frente al problema de la naturaleza. En palabras de Parra:

Se descubrió lo siguiente en el siglo XXI; que la naturaleza es finita, que el mar tiene fondo. En el siglo XIX los poetas hablaban del mar sin fondo. Esa expresión ustedes la tienen que haber encontrado en alguna parte todavía. No le crean a los poetas que hablan del mar sin fondo; el mar tiene fondo y, en la actualidad, está transformado en un basural. (id.: 47)

Ante la certeza del problema de la naturaleza, que implica la incertidumbre de la supervivencia del hombre, comienza a gestarse el proyecto antipoético. Así lo expone a las alumnas del liceo: 
Entonces me pareció que había un gran vacío, una gran grieta, entre la literatura y la vida real. Yo dije: "Esto no puede ser, los poetas nos están haciendo huevos de pato". Tendrá que existir una manera -pensaba yo- de llevar la vida tal cual a la poesía. Ese es el punto inicial. (id.: 51)

La antipoesía es el proyecto poético que surge de la crítica hacia la postura de la literatura frente a los problemas del mundo moderno: es un proyecto que se basa en acortar las distancias entre la poesía y la vida del día a día, que busca un lenguaje que logre hacer accesible la comunicación literaria a un amplio espectador, no sólo al lector culto, sino a todos aquellos a quienes debe llegar el mensaje antipoético. La intención de Parra es hacer una poesía cercana a la vida y transgresora de lo que se entendía por poético, a través de una textualidad que se define como anti-literatura, reescritura de la literatura, de los modelos y referentes, para "llevar la vida tal cual a la poesía”, y parte de esta vida es “el problema de la supervivencia, de la naturaleza”.

El problema de la supervivencia lo entenderemos, para el presente artículo, como resultado de la oposición entre lo material y lo ideal, que dominara gran parte del pensamiento moderno y que se constituyera en parte de la cosmología occidental nativa y que ha llevado al pensamiento de que los seres humanos forman comunidades de individuos relativamente independientes entre sí y su contorno (Skewes 2010). Abordamos, desde esta perspectiva antropológica la visión de Parra del problema, a través de la relación del ser humano con lo no-humano, entendiendo esta última categoría como objetos materiales creados por el ser humano y los elementos naturales propios del ambiente en el cual se desenvuelven los seres humano.

A partir de la determinación de la visión del poeta con respecto a la función de la poesía como "corrección de la sociedad”, y del poeta como "levantador de pancartas”, la visión crítica de la literatura ajena a la realidad y el proyecto de acercar la literatura a la vida real, realizamos una primera lectura interpretativa del texto, concluyendo cinco categorías de signos propios del problema a analizar: presencia de objetos cotidianos, personificación y valoración de la naturaleza, desacralización del sujeto y objeto religioso, crítica del mundo y del individuo moderno y la textualidad antipoética.

\subsection{Presencia de objetos cotidianos}

La palabra arcoiris no aparece en ninguna parte,

Menos aún la palabra dolor,

La palabra torcuato.

Sillas y mesas sí que figurarán a granel,

¡Ataúdes! ¡útiles de escritorio!

Lo que me llena de orgullo

Porque, a mi modo de ver, el cielo se está cayendo a pedazos.

(“Advertencia al lector”, Parra 1998: 81)

Podemos considerar este fragmento como un enunciado metatextual del proyecto antipoético, es decir, define y caracteriza la antipoesía. Bajo nuestro interés, destacamos que en la poesía de Parra no se encuentran objetos característicos de la poesía, sino lo ausente, los objetos cotidianos, como sillas y mesas. El hablante, el poeta en esta interpretación, considera que "el cielo se está cayendo a pedazos”, 
entendemos, en el contexto de la postura ecológica de Parra, que se refiera al problema de la supervivencia y la naturaleza. Bajo esta concepción apocalíptica del mundo (Carrasco 1990: 230-241 y 1999: 95) el poeta expresa que en su textualidad, antipoesía, los lectores encontraremos "palabras" cotidianas, puesto que el poeta se relaciona con lo no-humano cotidiano, no onírico, místico, etéreo... ni con “arcoiris”; por el contrario, se relaciona con sillas, mesas, kioscos, árboles, escuelas públicas, moscas, cocinas, automóviles...

Dentro de los objetos creados por el hombre, encontramos, como expresa el fragmento, múltiples referencias a muebles. Las sillas y mesas rondan constantemente los poemas del libro, “Todo está igual, seguramente, / El vino y el ruiseñor encima de la mesa” ("Hay un día feliz”), "La mesa está puesta, muerde / La uva que te trastorna” (“Canción”), "Me río detrás de una silla, / Mi cara está llena de moscas.” ("Rompecabezas"), "Me abría paso a través de un bosque de sillas y mesas" ("Recuerdos de juventud”), "Yo pasaba las noches ante mi mesa de trabajo” ("El túnel"), "En que yo, como un esqueleto de pie delante de esa mesa del infierno" ("La trampa”).

Sillas y mesas son importantes para el hablante, debido a su profesión y gusto. En el poema "Autorretrato" el poeta se define como profesor, "Soy profesor de un liceo oscuro / He perdido la voz haciendo clases”, y por lo tanto, debía haber un escritorio, "Detrás de ese mesón inconfortable / Embrutecido por el sonsonete / De las quinientas horas semanales". En el poema "Epitafio" también se establece una relación de cotidianidad y afectividad con una actividad relacionada a la mesa, la comida, "Aunque devoto de la buena mesa; / De mejillas escuálidas”. Analizando estos objetos, como signos de lo no-humano, establecemos que el ser humano, en este caso el hablante -o bien podríamos decir que Parra establece una relación especial con ciertos objetos no-humanos, creados por el hombre y utilizados cotidianamente, que llegan a poseer una carga emocional por lo que representan. Por ejemplo, la mesa puede ser valorada como elemento de unión familiar, como en el poema "Hay un día feliz" o convertirse en un lugar de tormento, como es el caso del mesón de "Autorretrato".

La presencia de lo no-humano creado por el humano ronda como motivo de interés y atención del sujeto hablante, como lo demuestra en el poema "El peregrino", "Me encuentro en un desastroso estado mental, / Razono a mi manera; / Mientras digo estas cosas veo un bicicleta apoyada en un muro, / Veo un puente / Y un automóvil que desaparece entre los edificios.”. La creación poética, en Parra, no puede desprenderse de la vida cotidiana, de lo que está a su alrededor: el hablante es absolutamente consciente de lo no-humano que lo rodea, y esta conciencia no es normal, ni momentánea, por eso lo perturba.

En el poema "Hay un día feliz", encontramos un aspecto relevante para nuestra línea de interpretación: la relación del humano con lo no-humano era diferente, en el pasado los objetos tenían historia, "No se puede dudar, este es el reino / Del cielo azul y de las hojas secas / En donde todo y cada cosa tiene / Su singular y plácida leyenda”. Significando "leyenda" por historia o lo que se cuenta del objeto, encontramos un elemento interesante desde un código antropológico: los objetos efectivamente poseen una historia y es posible estudiarla. Kopytoff (1991) expresa que "las biografías de las cosas pueden destacar aquello que de otro modo permanece oscuro” (id.: 93). Bajo esta línea de interpretación, entendemos que lo no-humano, creado por el humano, es 
de valor en el texto de Parra; pero no todo lo creado por el humano, sino lo cotidiano, lo cercano, lo que forma parte de la realidad del ser común, como sillas y mesas. Estos objetos son importantes debido a la relación que establece el humano con ellas, porque, como expresa el hablante, poseen su "singular y plácida leyenda”, leyenda que seguramente incorpora lo "oscuro" que permanece oculto a primera vista en torno a la persona. ¿Acaso los objetos que poseemos, que nos gustan, apasionan, no "dicen algo" de nosotros y nuestra historia? Hay que recalcar, sin embargo, que en el poema "Hay un día feliz” la relación con el objeto se encuentra en el pasado, en el “día feliz”; este es un signo de crítica que será abordada más adelante.

\subsection{Personificación y valoración de la naturaleza}

¡Por qué te entregas a esa piedra

Como a un puñal envenenado,

Tú que comprendes claramente

La gran persona que es el árbol!

(“Defensa del árbol”, Parra 1998: 53)

Así como en la sección anterior destacamos los signos de sillas y mesas como elementos no-humanos creados por el ser humano; ahora seleccionamos el árbol como uno de los signos más relevantes de lo no-humano propio de la naturaleza.

En el fragmento de "Defensa del árbol” se encuentra el elemento clave del valor que se le otorga a la naturaleza en el libro de Parra: la personificación. Este poema corresponde a un reclamo, o sermón, que le expresa el hablante (destinador) a un niño (destinatario), por haber tirado una piedra a un árbol -o haber tenido la intención de hacerlo-. El árbol presenta una carga valorativa positiva, mientras que el niño negativa: el árbol es calificado más que como persona -por el recurso de la personificacióncomo "amigo", es "Quién no hace nunca daño a nadie / No se merece tan mal trato", “Debe ser siempre por el hombre / Bien distinguido y respetado”, es una gran persona ya que entrega fruta, leña en invierno, sombra en el verano, "Crea los vientos y los pájaros", siempre está al lado, es "Más fiel que el vidrio del espejo / Y más sumiso que un esclavo", por estas razones el hablante le dice al niño: "Piénsalo bien y reconoce / Que no hay amigo como el árbol”. El niño, por el contrario, es relacionado a un cuervo y como el más mal intencionado de Chile, "Seguramente que tu madre / No sabe el cuervo que ha criado, / Te cree un hombre verdadero, / Yo pienso todo lo contrario: / Creo que no hay en todo Chile / Niño tan mal intencionado.”. También lo caracteriza como un niño de origen europeo, y a través de la sátira se burla de la caracterización positiva que se hace comúnmente de un niño de estas condiciones: "Yo no comprendo, francamente, / Cómo es posible que un muchacho / Tenga este gesto tan indigno / Siendo tan rubio y delicado.”. Por último, es necesario destacar que la personificación y valoración positiva del árbol, llega a ubicarlo a nivel familiar, "Niño perverso que lo hiera / Hiere a su padre y a su hermano.”.

El árbol, signo que podemos interpretar como cualquier elemento natural, pasa a transformarse en materia prima para el ser humano. En "Solo de piano", se presenta un monólogo existencial, donde los objetos y sujetos, no-humanos y humanos, se encuentran incompletos. Situación que se sostiene en los último versos, "Yo quiero hacer ruidos con los pies / Y quiero que mi alma encuentre su cuerpo”. En relación a lo 
incompleto del árbol, de la naturaleza, establecemos que la crítica radica en la actitud del ser humano que no es capaz de ver al árbol más allá que en su funcionalidad como materia prima, "Ya que los árboles no son sino muebles que se agitan: / No son sino sillas y mesas en movimiento perpetuo". En el poema "Soliloquio del individuo", también interpretamos el árbol como objeto utilitario, "Buscar peces, pájaros, buscar leña, / (Ya me preocuparía de los demás asuntos.) / Hacer una fogata, / Leña, leña, dónde encontrar un poco de leña, / Algo para hacer una fogata, / Yo soy el individuo.”, "Alguien segregaba planetas, ¡Árboles segregaba! / Pero yo segregaba herramientas, / Muebles, útiles de escritorio, Yo soy el individuo.”.

En el poema "Se canta al mar", determinamos una personificación del mar. El hablante relata cuando conoce el mar en la niñez en compañía de su padre. El mar se concretiza identificándolo como el mar que el niño conoce en Puerto Montt, camino a la Isla de Chiloé. De esta manera, no se habla del mar en sentido general, refiriéndose a sus características idealizadas en la poesía tradicional, sino que se lleva a una situación y lugar específico, por lo tanto, a la experiencia real y concreta del hablante. De esta manera, el niño conoce el mar del que habían hablado en la escuela y que aparecía mencionado en las cartas de amor de las hermanas: "De manera que nunca, ni por pienso, / Se conversó del mar en nuestra casa. / Sobre este punto yo sabía apenas / Lo que en la escuela pública se enseñaban / Y una que otra cuestión de contrabando / De las cartas de amor de mis hermanas.”. En el momento de conocerlo se produce, en palabras del hablante, un saludo entre el mar y él en la niñez:

Y en un instante memorable estuve

Frente a ese gran señor de las batallas.

Entonces fue cuando extendí los brazos

Sobre el haz ondulante de las aguas,

Rígido el cuerpo, las pupilas fijas,

En verdad sin fin de la distancia,

Sin que en mi ser moviérase un cabello,

¡Cómo la sombra azul de las estatuas!

Cuánto tiempo duró nuestro saludo

No podrán decirlo las palabras.

(Parra 1998: 66)

En el saludo reside la personificación del mar y de la naturaleza representada en él. En este poema el humano establece un vínculo memorable con lo no-humano, y viceversa, lo no-humano con lo humano. En los versos finales se expresa una reflexión, donde el hablante establece una relación entre su quehacer poético y el mar: "Sólo debo agregar que desde aquél día / Nació en mi mente la inquietud y el ansia / De hacer en verso lo que en ola y ola / Dios a mi vista sin cesar creaba. / Desde ese entonces data la ferviente / Y abrasadora sed que me arrebata: / Es que, en verdad, desde que existe el mundo, / La voz del mar en mi persona estaba.”. En el último verso interpretamos la "voz del mar" como la poesía en estrecha relación con el mar, en representación de la naturaleza, que es parte del hablante, pero que en la experiencia del "saludo" con el mar, aflora.

Antítesis a la personificación del no-humano propio de la naturaleza la encontramos en el poema “Oda a unas palomas”. Este poema, como expresa De Costa (1998: 29), corresponde a un texto "anti-Neruda": 
En esta composición de la segunda sección del libro -sección que el propio autor califica de "transicional"- se puede ver el mecanismo de la transformación de "poesía” en "antipoesía”. El modelo a transformar, como sugiere el título, es Neruda, el autor de las proyectadas Odas elementales, con su recién estrenado discurso hablado, de "hombre sencillo", en que el hablante se percata de las cosas más ordinarias para descubrir en ellas su belleza, su ignorada dimensión "poética”. En este sistema, el poeta es el descubridor, el mago revelador. (id.)

De esta manera Parra instaura un discurso transgresor del discurso literario establecido, satirizando el modelo textual y extratextual del verosímil artístico y cultural (Carrasco 1990: 26). La transgresión también lleva a no idealizar lo que comúnmente se idealiza en la poesía; en este caso, se transgrede la norma de idealización de la oda y, por supuesto, la idealización del objeto cotidiano en las odas de Neruda. En palabras de De Costa, “Un 'poeta' (Neruda) las [palomas] puede idealizar; el 'antipoeta’ (Parra) las ve de otro modo, más real: como unos animales asquerosos y sucios" (1998: 31). Por esta mirada "real" no personifica a la paloma en la oda, sino que se mofa de ellas, "Qué divertidas son / Estas palomas que se burlan de todo, / Con sus pequeñas plumas de colores / Y sus enormes vientres redondos".

A través de esta antítesis de personificación también establece una relación importante entre el humano y lo no-humano, en el marco de la concepción de poesía. Para el humano-poeta, la relación con la paloma es falsa, justificada y establecida en virtud de un tipo textual llamado "oda”: para el humano-antipoeta, la relación con la paloma es concreta, cotidiana, correspondiente a lo que el antipoeta observa en la realidad. La visión de "llevar la poesía a la vida”, lo lleva al antipoema, y a burlarse de la visión idealizada de la oda, "Más ridículas son que una escopeta / O que una rosa llena de piojos. / Sus estudiados vuelos, sin embargo, / Hipnotizan a mancos y cojos / que creen ver en ellas / La explicación de este mundo y el otro.”. En este poema interpretamos una crítica a la relación que establece el humano-poeta con lo nohumano, en este caso, no-humano propio de la naturaleza, debido a la funcionalidad o utilización que hace el humano-poeta del objeto. Así como en el caso del árbol en el poema “Sólo de piano”, donde el árbol no es más que sillas y mesas: la paloma en una oda es un objeto al cual se le atribuyen características irreales, idealizadas, con el objeto de crear un texto poético de exaltación. La crítica a la relación, en este caso, radica en la ausencia de relación verdadera, íntima, como se presenta con el mar en el poema "Se canta al mar", y en la funcionalidad otorgada al objeto.

Otro signo de crítica a la relación que establece el humano con lo no-humano propio de la naturaleza, es en la "intimidad" de esta relación en el pasado. En el poema "Se canta al mar", la intimidad se da en el pasado del hablante, en su niñez; en el poema "Hay un día feliz" hay un par de versos donde el hablante, que relata su regreso a la aldea, se relaciona individualmente con ovejas y hojas, “Al establo volvían las ovejas. / Las saludé personalmente a todas” y "Recordé el mar y enumeré las hojas / En homenaje a mis hermanas muertas”. Además, recordemos que en este poema también está presente la relación con lo no-humano creado por el humano "En donde todo y cada cosa tiene / Su singular y plácida leyenda”. La leyenda también está presente en un signo ya considerado en el análisis, el árbol, "Lo reconozco bien, este es el árbol / Que mi padre plantó frente a la puerta”, no es cualquier árbol, es 
el árbol que plantó el padre y que se vio crecer mientras vivía en la aldea, ese árbol posee una biografía y una relación especial con el hablante.

\subsection{Desacralización del sujeto y objeto religioso}

Un cura, sin saber cómo,

Llegó a las puertas del cielo,

Tocó la aldaba de bronce,

A abrirle vino San Pedro:

(...)

Viviste entre los humanos

Del miedo de los enfermos

Vendiendo medallas falsas

Y cruces de cementerio.

(“Desorden en el cielo”, Parra 1998: 69)

Carrasco considera que una de las características esenciales de la antipoesía de Parra es la desmitificación, la actitud desacralizadora, no sólo de la literatura, sino también de lo sagrado (1990: 166-207). Dentro de los antipoemas, encontramos los “antipoemas religiosos” -así como los “ecopoemas”-, con respecto a estos Carrasco expone, "El antipoeta se refiere a Dios, a los sacerdotes, a los creyentes, a distintos símbolos sacros (en especial a la cruz), a los santos, a formas rituales, etc., en forma chocarrera. Su imagen de la religión católica es simple, ingenua, incluso burda (...)” (id.: 172).

En "Desorden en el cielo" determinamos el elemento desacralizador del sujeto y objeto religioso. El hablante lírico es indeterminado, por lo que podemos interpretarlo como la voz del poeta, quien relata la llegada de un cura a las puertas del cielo. La desacralización se encuentra desde el primer verso, donde se expresa que el cura no sabe cómo llegó al cielo, desde este momento, el hablante determina al cura como totalmente consciente de su carencia de mérito para acceder al cielo. Las críticas que se presentan al cura son: la intención de comprar a Dios, "Cristo no se compra / Con mandas ni con dinero"; la palabra falsa ante Dios, "Y no se llega a sus pies / Con dichos de marinero.”; el estilo de vida opulento y el aprovechamiento de ignorancia, el sufrimiento y fidelidad de sus siervos, "Viviste entre los humanos / Del miedo de los enfermos / Vendiendo medallas falsas / Y cruces de cementerio. / Mientras los demás mordían / Un mísero pan de afrecho / Tú te llenabas la panza / De carne y de huevos frescos.”. Luego de que San Pedro le recrimina, además, de pecar de lujuria, termina llamándolo “¡Murciélago del infierno!”; y lo envía al infierno a través de un portazo.

La desacralización del objeto religioso, medallas y cruces, obedece a la acción del sacerdote que vive de la venta de estos objetos. El antropólogo Geary (1991) presenta un interesante ensayo sobre la mercantilización de reliquias en la Edad Media, en relación a este podemos establecer los objetos religiosos del poema-medallas y cruces de cementerio- como reliquias, es decir, trozos de tela, objetos que pertenecieron a un santo o sirvieron para su martirio, otros materiales relacionados e, incluso, partes de sus cuerpos, que no poseen un valor económico intrínseco, sino un valor basado en un conjunto de creencias específicas compartidas en torno al objeto (id.: 217 y 218). Estas reliquias pasan a ser mercancías, es decir, bienes destinados a la circulación e intercambio, a través de la venta. En el poema, el sacerdote transforma este objeto 
sacro en medio de intercambio económico, él "vende” la reliquia, debido a que existe un comprador; quién, se deduce, es un creyente en la reliquia. La desacralización no sólo se expone por la venta, sino por el calificativo que le otorga el poeta al objeto: falsedad. El objeto no-humano, es considerado sacro por el ser humano, esto en contexto de una religión: la crítica radica en la falsedad de la creencia en torno al objeto y en el aprovechamiento del valor que le confieren los creyentes al objeto, por parte del humano que lo vende -en esta ocasión el "cura”-.

La desacralización del objeto es más fuerte, culturalmente, en torno a las "cruces de cementerio". La cruz, como signo, es significante de un referente cultural e institucional muy fuerte en la sociedad chilena: Jesús y la Iglesia Católica. Es la Iglesia Católica uno de los agentes que mercantilizó las reliquias en la Edad Media (cfr. Geary) y quien se ha apropiado del signo de la cruz en sus iglesias y medallas. En el poema, la cruz es objeto que vende el cura en una ubicación específica: el cementerio. Del poema se interpreta una fuerte crítica frente a la actitud del sacerdote en su papel de guiador de fieles: la crítica la realiza en voz de San Pedro, que le niega la entrada al cielo por la venta, en este caso, de las cruces del cementerio. En el momento de la muerte de un familiar cuando el católico debe mediar con el sacerdote para defender la memoria de su pariente y sus derechos de ser enterrado en un cementerio, de recibir una "santa sepultura". Este rito es transformado en mercantilización a través de la venta de la "cruz de cementerio” y, la voz del poeta critica esta acción a través de la voz de San Pedro.

Para concluir el análisis del poema, nos referiremos al título: "Desorden en el cielo” nos remite a una situación de caos, no normalidad o contaminación. Con respecto a la noción de "desorden", interpretado como caos, Douglas (1973) presenta una reflexión de la cual nos basaremos para la interpretación. El autor expresa que cada sujeto, o sociedad, construye un mundo estable en que los objetos tienen formas reconocibles, están localizados y poseen permanencia, de este modo percibimos y construimos la realidad a través de la aceptación o el rechazo (id.: 55 y 56), bajo esta concepción de “esquematización” de la realidad, el “desorden” corresponde a lo fuera de lugar, la anomalía. Llevando este análisis al poema interpretamos que no es normal que San Pedro niegue la entrada al cielo a un representante de Dios y que no es normal que un representante de Dios, de las características descritas en el poema, llegue a las puertas del cielo. El desorden corresponde a la anormalidad de la situación que describe el hablante en el poema, ante este desorden es San Pedro quien establece el orden a través de la negación y el traslado del sacerdote al infierno. Considerando al sacerdote -con toda la carga negativa que conlleva en el texto como persona- en el infierno, volvemos a establecer el orden: de nuestro esquema moral cristiano, que permanece estable. Sin embargo, como lectores, nuestro esquema de poesía y de valoración social de la Iglesia Católica continúa en "desorden"; en este "desorden" se refleja la actitud antipoética. Recordemos que Carrasco (1990 y 1999) afirma que el texto antipoético se constituye en torno a otro u otros textos, a través de la reescritura de un texto, género, estereotipo, referente o conjunto de estos; en este caso es el referente religioso, llamado cura por el hablante, quien constituye un texto social que es deformado satíricamente por Parra. De este modo se cumple la función “de pancarta” del proyecto antipoético, “(...) el antipoema se construye con lo que en realidad interesa comunicar: con los elementos de la marginalidad, de la protesta, de la trasgresión: los posibles textuales excluidos del verosímil literario de nuestra sociedad, es decir, lo no dicho por la literatura de la 
época.” (Carrasco 1990: 70). Afirmamos nuevamente, a través de este último análisis, que por medio del poema "Desorden en el cielo" se presenta una crítica al ser humano en su relación con lo no-humano, en este caso objeto religioso: la crítica recae en la “sacralización” del objeto; la enseñanza, en la “desacralización”. Esta consiste -bajo la línea de interpretación del presente artículo- en la relación cotidiana, verídica con lo no-humano: si el "cura” no se comporta como debe, bajo la mirada de San Pedro, no debemos considerarlo en camino al cielo; si las medallas y las cruces de cementerio son vendidas por el cura, no debemos sacralizarlas.

\subsection{Crítica del mundo e individuo moderno}

Como queda demostrado,

El mundo moderno se compone de flores artificiales,

Que se cultivan en unas campanas parecidas a la muerte,

Y está formado por estrellas de cine,

Y de sangrientos boxeadores que pelean a la luz de la luna,

Se compone de hombres ruiseñores que controlan la vida económica de los países

(...)

El mundo moderno es una gran cloaca

(“Los vicios del mundo moderno”, Parra 1998: 108)

En esta sección se analizarán los poemas "Los vicios del mundo moderno" y "Soliloquio del individuo”. Estos textos pueden ser considerados los más relevantes en cuanto crítica a la relación del humano con lo no-humano.

"Los vicios del mundo moderno" trata sobre los vicios que observa el hablante en el mundo moderno. Nos interesa la mirada de "vicio de la modernidad" de los signos en relación a la economía. Parte el poema refiriéndose a los delincuentes:

Los delincuentes modernos

Están autorizados para concurrir diariamente a parques y jardines.

Provistos de poderosos anteojos y relojes de bolsillo

Entran a saco en kioscos favorecidos por la muerte

E instalan sus laboratorios entre los rosales en flor.

Desde allí controlan a fotógrafos y mendigos que deambulan por los alrededores

Procurando levantar un pequeño templo a la miseria

Y si se presenta la oportunidad llegan a poseer a un lustrabotas melancólico.

La policía atemorizada huye de estos monstruos

En dirección del centro de la ciudad

En donde estallan los grandes incendios de fines de año

Y un valiente encapuchado pone manos arriba a dos madres de la caridad.

(Parra 1998: 106)

Los delincuentes modernos ocupan los lugares comunes y comunitarios: parques y jardines. Interrumpen estos escenarios de tranquilidad y recreación, controlando a los personajes relacionados a la miseria, que habitualmente se hallan en estos lugares comunitarios: fotógrafos, mendigos y lustrabotas. Los delincuentes son poderosos, en el sentido que no existe ninguna autoridad que los detenga y la policía, signo de control y seguridad ciudadana, es inferior al poder de los delincuentes y se da la 
situación inversa a la que un ciudadano esperaría: los policías son quienes huyen de los delincuentes.

En cuanto al análisis de la relación entre el humano y no-humano, en este poema establecemos una crítica al humano que se relaciona con lo no-humano "ajeno": se establece una relación de propiedad y hurto. La crítica se enfoca en los humanos que establecen relación con lo ajeno, sin respetar las normas sociales -representados por la policía-, y con lo ajeno de otros humanos de menor poder adquisitivo, como son las madres de la caridad.

También determinamos una serie de versos que justifican una interpretación de crítica del poder económico y, en especial, de la relación del humano poderoso con el resto. Los versos son, "Los vicios del mundo moderno: /.../ Los trucos de la alta banca", "El comercio clandestino de blancas realizado por sodomitas internacionales", "El afán desmedido de poder y de lucro, / La carrera del oro, / La fatídica danza de los dólares”, "Se compone de hombres ruiseñores que controlan la vida económica de los países” y “Los restaurantes de lujo están atestados de cadáveres digestivos”. Como se observa, dentro de los vicios del mundo moderno la economía está presente, relacionada a los signos: banca, comercio, poder y lucro, oro, dólares, vida económica y restaurantes de lujo. Estos signos presentan una carga negativa, a través de las calificaciones: "trucos" para banca, "clandestino" para comercio, "carrera" para oro, “fatídica danza” para dólares, "ruiseñores que controlan” para vida económica y “atestados de cadáveres digestivos” para restaurantes de lujo. Interpretamos que se critica la relación que establece el humano con lo no-humano a través de la actividad económica. En este ámbito, ya no se trata de lo ajeno o hurto, sino de "mal uso", del mal comportamiento en relación al capital: se relaciona la economía con truco, clandestino, competencia, danza fatal, control de seres ostentosos. El objeto nohumano, ya sea creado por el hombre o propio de la naturaleza, pierde su propiedad valorativa o personificación presente en los análisis previos, en este caso sólo forman parte de una relación de poder que se traduce en capacidad de control y adquisición del humano poderoso.

En el poema "Soliloquio del individuo" Parra repasa la historia de la humanidad, desde sus inicios en la Edad de Piedra hasta el momento de producción textual -la Edad de la Tecnología- (De Costa 1998: 39). Interpretamos que la humanidad establece una relación de dependencia, utilidad y hastío con lo no-humano, produciéndose una pérdida de sentido.

Antes de analizar la proyección temporal de la relación entre humano y no-humano que se interpreta en el texto, cabe analizar semióticamente el verso que se repite dentro del poema, otorgando no sólo fuerza métrica, sino también semántica, "Yo soy el Individuo". Con este verso determinamos al hablante como "el Individuo", no un individuo indeterminado, sino determinado por el carácter de sustantivo personal que le confiere el uso de mayúscula. El hablante representa a la Humanidad, que como suma de individualidades ha recorrido un camino histórico y cultural en torno a su relación con lo humano y no-humano -según la línea de interpretación del presente estudio-.

El Individuo comienza viviendo en una roca, grabándola, "Yo soy el Individuo. / Primero viví en una roca / (Allí grabé algunas figuras)". La relación con lo nohumano natural parte de una utilidad; es el lugar que habita y utiliza para expresarse. Sin embargo, el Individuo no está a gusto y realiza una búsqueda de algo mejor, una 
búsqueda que permanece en el Individuo a lo largo del desarrollo del texto, "Luego busqué un lugar más apropiado. / Yo soy el Individuo". A continuación se reafirma la relación utilitaria, ya analizada con anterioridad, "Primero tuve que procurarme alimentos, / Buscar peces, pájaros, buscar leña”. En una situación de soledad, recurre a la búsqueda de otra roca, donde también graba figuras, sin embargo, vuelve a aburrirse, "Pero no. Me aburrí de las cosas que hacía, / El fuego me molestaba, / Quería ver más, / Yo soy el Individuo”. Realiza un viaje en búsqueda del pueblo que necesitaba, "Una tribu”, y ve que ahí hacen cosas similares a las que él hacía, todas en relación de utilización y dependencia de lo no-humano natural. Esta tribu le pregunta por su origen y él contesta en relación al futuro, "Me preguntaron de dónde venía. / Contesté que sí, que no tenía planes determinados, / Contesté que no, que de ahí en adelante.”, en esta repuesta interpretamos otra crítica al humano, representado por el Individuo: la de no mirar al origen sino pensar solamente en función del futuro, y, relacionando a lo ya analizado, pensar en función de la búsqueda.

Luego de esta primera etapa de utilización y dependencia de lo no-humano natural, se presenta lo no-humano creado por el humano: la herramienta. Pule un trozo de piedra, del que interpretamos hace una herramienta con la que corta árboles. De esta creación, no sólo hace objetos, también crea una parte de su vida en relación a la herramienta: el trabajo, “Tomé un trozo de piedra que encontré en un río / Y empecé a trabajar con ella, / Empecé a pulirla, / de ella hice una parte de mi propia vida.”. Gracias a la herramienta, el Individuo puede navegar y busca cosas, hasta que se aburre de la naturaleza, "Hasta que empecé a aburrirme nuevamente. / Las tempestades aburren, / Los truenos, los relámpagos, / Yo soy el Individuo.”. De este aburrimiento surge el intelecto, la capacidad de pensar, podemos interpretar que la filosofía, "Bien. Me puse a pensar un poco, / Preguntas estúpidas se me venían a la cabeza, / Falsos problemas.”. Entonces retoma la búsqueda, ahora de una nueva tribu; sin embargo, el sujeto no la encuentra, perdiendo la fe en el objeto de deseo, "Para ver hay que creer (...)”, le dicen. En la pérdida de fe, comienza a desarrollar más su capacidad de crear objetos, "Inventé unas máquinas, / Construí relojes, / Armas, vehículos, Yo soy el Individuo.”. A través de la construcción el sujeto se distancia de la búsqueda que guiaba su actuar; su deseo de búsqueda se transforma en un deseo de construcción, que lo lleva a alejarse de lo religioso y la naturaleza, "Apenas tenía tiempo para enterrar a mis muertos, / Apenas tenía tiempo para sembrar, / Yo soy el Individuo”. Esta etapa se prolonga y acontecen catástrofes naturales y humanas, "Luego vinieron unas sequías, / Vinieron unas guerras, / Tipos de color entraron al valle / Pero yo debía seguir adelante, / Debía producir.” Su actividad de producción lo absorbe y la ciencia progresa; en el torbellino de producción ya no hay retorno, ha abandonado lo trascendental representado en el deseo de búsqueda y lo religioso, "Las religiones pasaron de moda, / Buscaban dicha, buscaban felicidad, / Yo soy el Individuo.”.

En un estado de conciencia, detiene la construcción y observa. La búsqueda imperiosa, su necesidad de hacer, poseer y avanzar lo conduce a mirar donde no debía y lo que ve le espanta, al punto de pensar que es mejor volver al inicio y comenzar nuevamente con su historia, "Yo soy el Individuo. / Miré por una cerradura, / Sí, miré, qué digo, miré, / Para salir de la duda miré, (...) / Mejor es tal vez que vuelva a ese valle, / A esa roca que me sirvió de hogar, / Y empiece a grabar de nuevo, / De atrás para adelante grabar / El mundo al revés. / Pero no: la vida no 
tiene sentido.”. Interpretamos que el sujeto ha desarrollado una vida alejada de lo trascendente, guiada por la inconformidad representada en la búsqueda y por el materialismo, representado en la necesidad de construir la herramienta. Y el acto de mirar por la cerradura corresponde a realizar una mirada retrospectiva y "prohibida”, en sentido que corresponde a una perspectiva que ha estado ausente de su vida, nunca se ha detenido a mirarse y mirar su vida como construcción de su actuar, por eso surge la duda y mira por un espacio tan pequeño como una cerradura. Es una mirada trascendente que lo lleva a desear volver al inicio, a obtener otra oportunidad; sin embargo, el último verso -la última reflexión- se traduce en la imposibilidad, en la pérdida de sentido. En este momento el sujeto se quiebra, pierde el sentido y la autoafirmación personal "Yo soy el individuo" se desvanece... la revelación fue destructiva, no hay posibilidad de volver a Ser ni Hacer.

En el poema determinamos a un humano que avanza vertiginosamente en relación de dependencia y utilidad de lo no-humano natural, para la creación de lo no-humano objeto: es una relación superficial, contraria a la íntima de "Se canta al mar" o "Defensa del árbol”. La crítica es más intensa que en "Hay un día feliz”, "Desorden en el cielo”, “Odas a unas palomas” o "Los vicios del mundo moderno”, tal vez por esta razón es el texto con que se termina el libro: corresponde a la última pancarta que levanta el poeta para intentar despertar la conciencia del Individuo. Es el poeta el que ha "mirado" y conoce la imposibilidad de empezar nuevamente, por esto la pérdida de sentido del sujeto textual. Sin embargo, podemos considerar al poeta extratextual- como un visionario, que conoce cuál será el fruto del hombre actual, pero que no ha perdido el sentido: la esperanza. Por eso levanta la pancarta, su última pancarta: recuperar al Individuo.

\title{
3.5. Textualidad antipoética
}

\author{
Una vez andando \\ Por un parque inglés \\ Con un angelorum \\ Sin querer me hallé. \\ (“Sinfonía de cuna”, Parra 1998: 51)
}

Se ha seleccionado este fragmento del poema "Sinfonía de cuna” por representar una de las características textuales propias de la antipoesía, la transgresión de los referentes. En este caso, se presenta una textualidad que De Costa ha calificado como “anti-Mistral” (1998: 24), y corresponde a la misma estrategia de transgresión que se presenta en "Oda a unas palomas". La canción de cuna debiera ir destinado a un infante y contener un mensaje acorde a la edad; situación que se presenta en el modelo de textos de Gabriela Mistral: Canciones de cuna.

En "Sinfonía de Cuna" se presenta a un hablante que relata su encuentro con un ángel y como se burla de él. El elemento más interesante es la desacralización de la poesía en relación a lo inmaterial. Recordemos que en la antipoesía encontramos sólo referencias reales: la relación del humano es con lo no-humano real, carnal, cotidiano. Por esta razón, en el texto el ángel posee plumas “duras como cascarón de un pez”. Bajo este ejemplo podemos sintetizar la funcionalidad de las estrategias textuales utilizadas en el libro como propias de la antipoesía: la desacralización 
y desmitificación; la presencia de una metalengua en relación a lo concreto y cotidiano; la desmitificación de la literatura y sus referentes tradicionales; un lenguaje coloquial, cercano a un lector no necesariamente culto; el uso de la narración como antítesis de lo lírico, con el objeto de narrar historias; un hablante indeterminado -en la mayoría de los textos- que se puede interpretar como la voz del poeta que, por supuesto, presenta una actitud de crítica, que podemos relacionar con el acto de "levantar pancartas".

\section{CONCLUSIONES}

En el texto Poemas y antipoemas de Nicanor Parra, establecemos una mirada crítica de la relación del humano con lo no-humano, que se manifiesta en el mensaje y las estrategias textuales propias de la antipoesía.

El mensaje se visibiliza a través de dos vertientes: la crítica y la ejemplificación. La crítica se da hacia la relación superficial y utilitaria que establece el humano con lo no-humano creado por el hombre; mientras que la ejemplificación se traduce en el mensaje de la posibilidad de una relación experiencial del humano con lo no-humano que se concretiza en el desarrollo de una historia en común, donde se reconoce la historia particular del no-humano.

Lo no-humano se hace presente en lo concreto y cotidiano que rodea y convive con el humano en su día a día; por esta razón, hemos determinado que una de las categorías de análisis corresponde a la Presencia de objetos cotidianos. Parte de estos corresponden a lo no-humano natural, cuya presencia categorizamos como Personificación y valoración de la naturaleza: a través de la personificación del nohumano natural se presenta una valoración de éste y la posibilidad de la relación íntima, que supera la utilitaria.

Un aspecto de la crítica se manifiesta en la Desacralización del sujeto y objeto religioso. La mirada aguda y perspicaz del hablante recae en aquellos sujetos que establecen una relación falsa y de utilidad con lo no-humano, otorgándole un valor de mercancía en un contexto religioso, aprovechándose de la fidelidad e ignorancia de los miembros de la comunidad.

Se establece una Crítica del mundo e individuo moderno en torno al poder económico, ya sea mediante la relación de hurto de lo no-humano ajeno o el abuso de poder que ejerce aquel humano que acumula lo no-humano, adquiriendo mayor poder adquisitivo y lujo. También se presenta una crítica al individuo moderno en cuanto al desarrollo de su existencia: se critica su desarrollo vital en base a una relación utilitaria y superficial con lo no-humano, basado en la búsqueda insistente y el descontento. Ante esta situación, el hablante se traduce en un visionario que es capaz de prever las consecuencias de esta relación y hace un llamado de alerta - "levantamiento de pancarta”- que corresponde a un mensaje a favor de un nuevo comenzar, previo a la pérdida de sentido.

La mirada crítica abordada temáticamente en las categorías anteriores se traduce en una Textualidad antipoética. Esta presenta las siguientes características: desacralización y desmitificación de la poesía y sus referentes; la presencia de una metalengua en relación a lo concreto y cotidiano; un lenguaje coloquial, cercano a un lector no necesariamente culto; el uso de la narración como antítesis de lo lírico, con el objeto de narrar historias; un hablante indeterminado -en la mayoría de los 
textos- que se puede interpretar como la voz del poeta que, por supuesto, presenta una actitud de crítica.

El poemario corresponde a una textualidad transgresora de la literatura, que critica el alejamiento de la literatura de la vida real y cotidiana: es un proyecto de acercamiento literario a la vida "real", con sus pequeñas y grandes verdades -los objetos simples como sillas y mesas, y los vicios del mundo moderno- $\mathrm{y}$, no menos importante, un "levantamiento de pancarta”.

\section{OBRAS CITADAS}

\section{Fuente primaria}

Parra, Nicanor.1998. Poemas y antipoemas (1954). Madrid: Ediciones Cátedra.

\section{Fuentes secundarias}

Araya, Juan. 2008. "Nicanor Parra. De la Antipoiesis a la Ecopoiesis”. Estudios Filológicos. 43: 9-18.

Ayala, Matías. 2005. "Nicanor Parra, nacionalista: entre la enseñanza pública y la poesía popular (notas)”. Revista Chilena de Literatura 66:107-117.

Carrasco, Iván.1990. Nicanor Parra: La escritura antipoética. Santiago: Editorial Universitaria. . 1999. Para leer a Nicanor Parra. Santiago: Editorial Cuarto Propio.

De Costa, René. 1998. "Introducción: Para una poética de la (anti)poesía”. Nicanor Parra. Poemas y antipoemas (1954). Madrid: Ediciones Cátedra, S.A. 9-40.

Douglas, Mary.1973. Pureza y peligro. Un análisis de los conceptos de contaminación y tabú. Madrid: Siglo XXI.

Eco, Umberto. 1992. Los límites de la interpretación. Barcelona: Lumen.

Geary, Patrick. 1991. "Mercancías sagradas. La circulación de las reliquias medievales”.La vida social de las cosas. Perspectiva cultural de las mercancías. Ed. A. Appadurair. México D.F.: Grijalbo. 211-239.

Kopytoff, Igor. 1991. "La biografía cultural de las cosas: La mercantilización como proceso,”. La vida social de las cosas. Perspectiva cultural de las mercancías. Ed. A. Appadurai. México D.F.: Grijalbo. 89-123.

Morales, Leonidas. 1990. Conversaciones con Nicanor Parra. Santiago: Universitaria. 2012. "Nicanor Parra: el proyecto antipoético". Anales de Literatura Chilena 17:147-167.

Skewes, Juan. 2010. Programa asignatura: Antropología de las cosas que producen palabras. ICSO 405. Universidad Austral de Chile, Facultad de Filosofía y Humanidades, Escuela de Graduados.

Schopf, Federico. s.f. "Las huellas del antipoema”. Nicanor Parra. Rescatado el 12 de diciembre de 2013. <http://www.nicanorparra.uachile.cl>

Vásquez, Adolfo. 2012. "Nicanor Parra: antipoemas, parodias y lenguajes híbridos. De la antipoesía al lenguaje del artefacto”. Nómadas. Rescatado el 12 de diciembre de 2013. <http://dx.doi.org/10.5209/rev_NOMA.2012.41775> 